\title{
Chronic dexamethasone exposure retards growth without altering the digestive tract microbiota composition in goats
}

\author{
Canfeng Hua, Yali Geng, Qu Chen, Liqiong Niu, Liuping Cai, Shiyu Tao, Yingdong Ni ${ }^{*}$ (D) and Ruqian Zhao
}

\begin{abstract}
Background: Dexamethasone (Dex), an artificially synthetic cortisol substitute, is commonly used as an anti-inflammatory drug, and is also employed to mimic the stress state experimentally. It is well known that chronic stress disturbs the gut microbiota community and digestive functions. However, no relevant studies have been conducted in ruminants.

Results: In this study, a low dosage of Dex ( $0.2 \mathrm{mg} / \mathrm{kg}$ body weight, Dex group, $n=5)$ was consecutively injected intramuscularly for 21 days to simulate chronic stress in growing goats. Goats were injected with saline $(0.2 \mathrm{mg} / \mathrm{kg}$ body weight) as the control group (Con, $n=5)$. Dex-treated goats showed a higher number of white blood cells and blood glucose levels $(p<0.01)$, but lower dry matter intake (DMI) and body weight $(p<0.01)$ than those of saline-injected goats. Plasma cortisol concentration decreased significantly in response to the Dex injection compared to the control $(p<0.05)$. The Dex treatment did not change most ruminal volatile fatty acid (VFAs) concentrations before the morning feeding after $1-21$ days of treatment ( $p>0.05$ ); however, ruminal VFA concentrations decreased dramatically $2,4,6$, and $8 \mathrm{~h}$ after the morning feeding on day 21 of the Dex injections. In this study, chronic Dex exposure did not alter the community structure of microbes or methanogenes in the rumen, caecum, or colonic digesta. Only Prevotella increased on days 7 and 14 of Dex treatment, but decreased on day 21, and Methanosphaera was the only genus of methanogene that decreased.

Conclusions: Our results suggest that chronic Dex exposure retards growth by decreasing DMI, which may be mediated by higher levels of blood glucose and lower ruminal VFA production. Microbiota in the digestive tract was highly resistant to chronic Dex exposure.
\end{abstract}

Keywords: Chronic stress, Dexamethasone, Growth, Micobiota composition, Goat

\section{Background}

Cortisol is a stress hormone synthesized and released by the pituitary gland under stress conditions [1]. Stress induces metabolic disorders, such as diabetes and cardiovascular disease [2,3]. Acute stress-induced hyperglycemia is observed in many situations, such as sepsis, myocardial infarct, shock, stroke, and trauma [4-7]. A major mechanism by which cortisol regulates glucose metabolism is to inhibit insulin signaling, which promotes glucose transporter 4 expression on the cell surface $[8,9]$. Stress has significant negative impacts on feeding and ultimately livestock productivity, which reduce efficiency and energy for physical

\footnotetext{
* Correspondence: niyingdong@njau.edu.cn

Key Laboratory of Animal Physiology \& Biochemistry, Nanjing Agricultural University, Nanjing 210095, People's Republic of China
}

maintenance [10]. Stress inhibits growth hormone secretion by decreasing circulating somatostatin [2]. Dexamethasone (Dex) has been used to simulate stress conditions in non-ruminant and ruminant animals [11].

Microbiota play an important role in maintaining gut health and body homeostasis. Microbiota affect mucosal defense and inhibit the ability of enteric pathogens to colonize. Bäckhed et al. and Ley et al. reported that intestinal microbiota are associated with obesity and diabetes in germ-free mice $[12,13]$. Many metabolites in the intestine are synthesized by microbes, such as vitamins $\mathrm{K}$ and B complex [14].

Prolonged stressors can radically change the composition of the intestinal microbiota and significantly increase circulating levels of interleukin- 6 and monocyte chemoattractant protein-1, which are correlated with

(c) The Author(s). 2018 Open Access This article is distributed under the terms of the Creative Commons Attribution 4.0 International License (http://creativecommons.org/licenses/by/4.0/), which permits unrestricted use, distribution, and 
changes in Coprococcus, Pseudobutyrivibrio, and Dorea populations [15]. This disruption of microbiota increases tumor necrosis factor-alpha gene expression in colonic tissue and elevates susceptibility to enteric pathogens [16]. Söderholm et al. [17] suggested that stress can induce intestinal inflammation by impairing mucosal defenses against luminal bacteria. Stress affects the integrity of the mucosal immune system by increasing CD4+ $\mathrm{T}$ and CD19+ B cells in the large intestine [18]. Pitlik and Koren [19] hypothesized that all diseases alter microbiome composition, turning a healthy microbiome into a disease pathobiome.

The methane concentration in the atmosphere has increased since the agricultural and industrial revolution over 200 years ago. Methane emissions from ruminant livestock (cattle, sheep, and goats), which is produced by methanogenic archaea, is a major contributor to anthropogenic greenhouse gas emissions worldwide [20]. Ruminants emit about 100 million tons of methane per year, which corresponds to $\sim 20 \%$ of global methane emissions. Methane is also a net loss of feed energy to the animal [21]. However, research on how stress impacts methanogenes is lacking.

Many studies have investigated how the host impacts the intestinal microbiome [19, 22]. However, studies about stress impacting microbiota in goats are lacking. Therefore, the object of present study is to investigate the influence of chronic stress on the microbiota in the rumen, caecum, and colon of goats.

\section{Results}

Changes in the number of blood cells in response to Dex The number of white blood cells (WBCs) $(p<0.01)$, neutrophils, lymphocytes, and eosinophils $(p<0.05)$ increased significantly after 14 days $(p<0.05)$ and 21 days of Dex injections (Table 1). The number of red blood cells increased markedly after 14 days of Dex treatment $(p<0.01)$, and showed a trend to increase on day 21 of Dex treatment compared to that in control goats $(0.05<p<0.1)$ (Table 1$)$. Moreover, mean corpuscular hemoglobin concentration decreased after 14 and 21 days of Dex treatment $(0.05<p<0.1)$ (Table 1$)$.

\section{Changes in dry matter intake, body weight, and blood glucose concentration in response to Dex}

As shown in Fig. 1a, dry matter intake (DMI) $(p<0.05)$ and body weight $(p<0.01)$ decreased significantly after the Dex injections compared to those in the control group (Fig. 1a). Blood glucose level increased significantly after 21 days of Dex injections $(p<0.05)$ (Fig. 1c). However, blood cortisol level decreased significantly in response to Dex treatment $(p<0.05)$ (Fig. 1d).

\section{Ruminal $\mathrm{pH}$ and urea, ammonia, and VFA concentrations}

Dynamic changes in ruminal $\mathrm{pH}$ were detected at $0,2,4$, and $6 \mathrm{~h}$ after the morning feeding on days $1,7,14$, and 21 of the Dex injections. These results show that Dex increased ruminal $\mathrm{pH}$. Ruminal $\mathrm{pH}$ increased significantly $2 \mathrm{~h}$ after the morning feeding on days 1 and 14 of Dex treatment compared to that in the control $(p<0.05)$ (Fig. 2a and $c)$. The concentrations of ruminal urea and ammonia

Table 1 The component of blood cell

\begin{tabular}{|c|c|c|c|c|}
\hline & \multicolumn{2}{|l|}{ Day 14} & \multicolumn{2}{|l|}{ Day 21} \\
\hline & Con & Dex & Con & Dex \\
\hline$\overline{W B C(10 \wedge 9 / L)}$ & $13.34 \pm 1.19$ & $21.66 \pm 2.12^{*}$ & $10.13 \pm 1.64$ & $16.86 \pm 0.50^{* *}$ \\
\hline Neu\#(10^9/L) & $7.99 \pm 1.03$ & $13.83 \pm 1.93^{*}$ & $5.41 \pm 1.07$ & $9.88 \pm 0.36^{* *}$ \\
\hline Lym\#(10^9/L) & $4.64 \pm 0.32$ & $6.90 \pm 0.50^{* *}$ & $4.17 \pm 0.63$ & $6.07 \pm 0.19^{*}$ \\
\hline Mon\#(10^9/L) & $0.45 \pm 0.08$ & $0.60 \pm 0.02$ & $0.40 \pm 0.01$ & $0.48 \pm 0.03^{\#}$ \\
\hline Eos\#(10^9/L) & $0.14 \pm 0.01$ & $0.22 \pm 0.02^{*}$ & $0.09 \pm 0.02$ & $0.18 \pm 0.03^{*}$ \\
\hline Bas\#(10^9/L) & $0.12 \pm 0.02$ & $0.16 \pm 0.02$ & $0.09 \pm 0.02$ & $0.11 \pm 0.01$ \\
\hline $\mathrm{RBC}(10 \wedge 12 / L)$ & $14.88 \pm 0.77$ & $18.60 \pm 0.55^{* *}$ & $15.45 \pm 0.75$ & $17.17 \pm 0.33^{\#}$ \\
\hline $\mathrm{HGB}(\mathrm{g} / \mathrm{L})$ & $95.25 \pm 6.12$ & $99.80 \pm 3.53$ & $86.25 \pm 4.03$ & $87.20 \pm 1.36$ \\
\hline НСТ\% & $27.78 \pm 1.94$ & $28.26 \pm 1.27$ & $27.07 \pm 1.09$ & $27.90 \pm 0.75$ \\
\hline$M C V(f L)$ & $16.33 \pm 0.61$ & $15.22 \pm 0.45$ & $18.92 \pm 1.13$ & $15.83 \pm 0.34^{\#}$ \\
\hline$M C H(p g)$ & $5.98 \pm 0.27$ & $5.36 \pm 0.11^{\#}$ & $5.40 \pm 0.08$ & $5.08 \pm 0.12^{\#}$ \\
\hline $\mathrm{MCHC}(\mathrm{g} / \mathrm{L})$ & $344.75 \pm 6.22$ & $353.60 \pm 5.05$ & $297.40 \pm 7.27$ & $312.40 \pm 5.23$ \\
\hline RDW-CV\% & $23.85 \pm 0.77$ & $25.03 \pm 0.83$ & $24.38 \pm 0.99$ & $24.30 \pm 0.57$ \\
\hline RDW-SD(fL) & $15.23 \pm 0.80$ & $15.90 \pm 0.47$ & $18.22 \pm 1.39$ & $16.57 \pm 0.03$ \\
\hline
\end{tabular}

WBC White blood cells, Neu Neutrophil, Lym Lymphocyte, Mon Monocyte, Eos Eosinophilic, Bas Basophil, RBC Red blood cells, HGB Hemoglobin, HCT Hematocrit, MCV Mean corpuscular volume, MCH Mean corpuscular hemoglobin, MCHC Mean corpuscular hemoglobin concentration, RDW-CV Red blood cell distribution width, RDW-SD Standard deviation of RBC distribution width. Means \pm SE are plotted; $\# p<0.10,{ }^{*} p<0.05$, ** $p<0.01$ versus Con group 

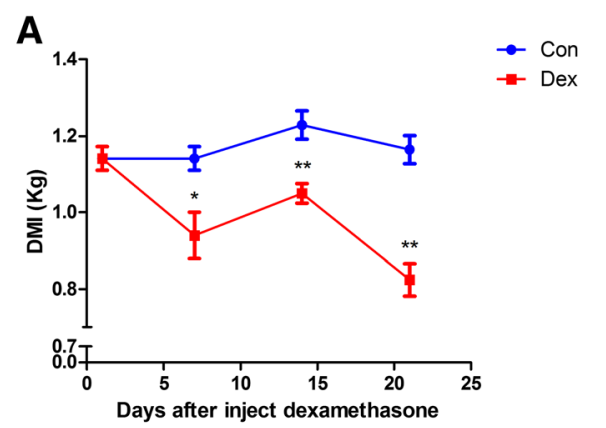

B

C

$\mathbf{D}$
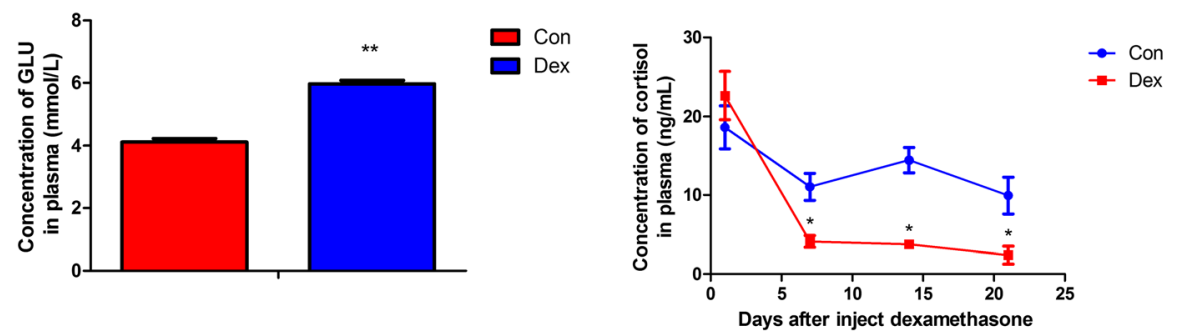

Fig. 1 a Dynamic alteration of DMl from goat treated with Dex or Con for 21 days. $\mathbf{b}$ Body mass of goats at the 21th day of the experiment. $\mathbf{c}$ Concentration of glucose in plasma at the 21 th day of the experiment. $\mathbf{d}$ Dynamic changes in the concentration of plasma cortisol from goat treat with Dex or Con for 21 days. Means \pm SE are plotted; ${ }^{*} p<0.10,{ }^{*} p<0.05,{ }^{* *} p<0.01$ versus Con group

were not altered by Dex treatment compared to the control $(p>0.05)$ (Additional file 1: Figure S1 and Additional file 2: Figure S2). The VFA concentrations in ruminal fluid remained unchanged before the morning feeding on days $1,7,14$, and 21 of the Dex injections $(p>$ 0.05) (Additional file 3: Figure S3). However, the concentrations of total ruminal VFAs, acetate, propionate, isobutyrate, butyrate, isovalerate, valerate and caproate decreased significantly $0,2,4,6$, and $8 \mathrm{~h}$ after the morning feeding on day 21 of the Dex injections $(p<0.05)$ (Fig. 3ah). In contrast, the acetate/propionate ratio was unchanged by Dex treatment $(p>0.05)$ (Fig. 3i).
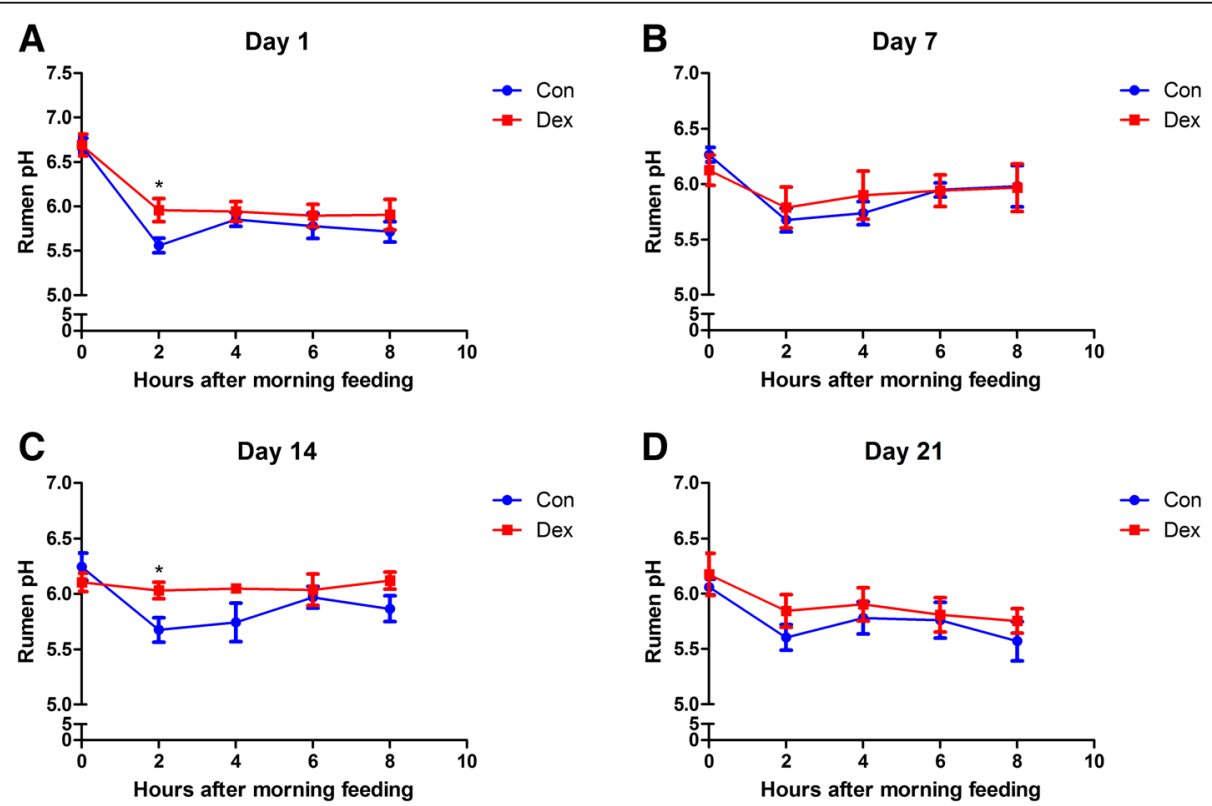

Fig. 2 Dynamic alteration of $\mathrm{pH}$ in rumen fluid from goat treated with Dex or Con, at 1, 7, 14, 21 day, after morning feeding. a Day 1. b Day 7. c Day 14. $\mathbf{d}$ Day 21. Means \pm SE are plotted; ${ }^{*} p<0.10,{ }^{*} p<0.05,{ }^{* *} p<0.01$ versus Con group 


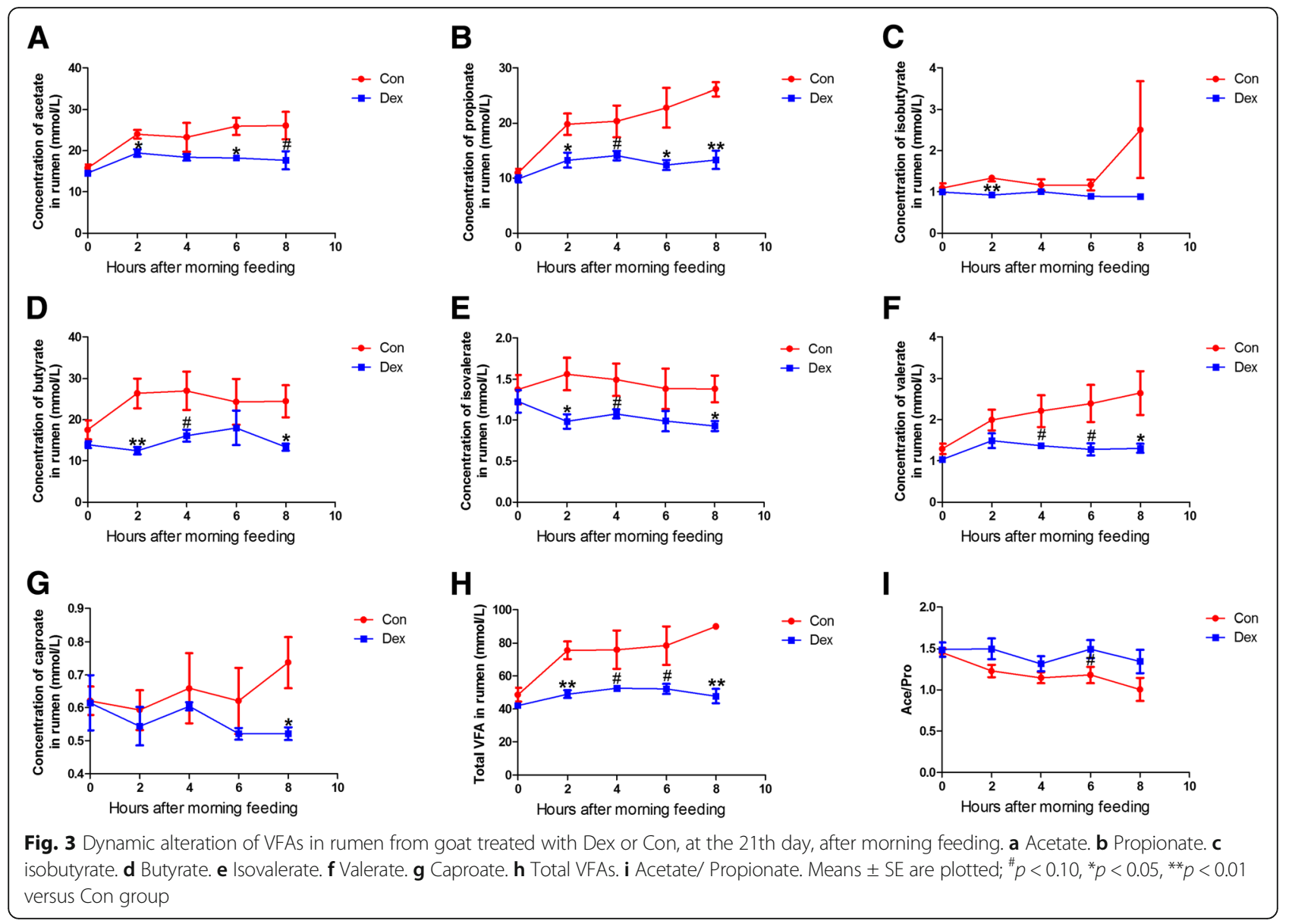

\section{Changes in VFA concentrations in feces, caecum, and the colonic digesta}

The concentrations of fecal butyrate and total VFAs decreased significantly in the Dex group compared to those in the control $(p<0.05)$ (Additional file 4: Figure $\mathrm{S} 4)$, whereas the acetate/propionate ratio remained unchanged by Dex $(p>0.05)$ (Fig. 3i). Only isovalerate concentration in the colonic digesta increased significantly in response to Dex $(p<0.05)$, whereas the other VFAs and total VFA contents in the colonic and caecal digesta were not affected by the 21-day Dex treatment $(p>0.05)$ (Table 2). None of the fecal VFAs changed, but butyrate decreased significantly after 14 days of Dex administration, leading to a reduction in total VFAs $(p<0.05)$ (Additional file 4: Figure S4D and H).

The composition of microbiota in ruminal fluid, caeca, and colonic digesta

The composition of microbiota was analyzed by nex t-generation sequencing. Figure 4 shows the PCoA analysis of the bacteria, and the Con and Dex groups were not separated. The composition of microbiota was not affected by the Dex treatment, as the phylum composition did not change (Additional file 5: Figure S5A-F).
Prevotella, and Selenomonas increased in abundance, whereas Desulfovibrio and Christensenella decreased in ruminal fluid after 7 days of Dex treatment (Fig. 5b). The abundances of Prevotella, Howardella, and Ruminococcus increased significantly after 14 days of Dex injections (Fig. 5c). The abundances of Prevotella, Clostridium_sensu_stricto_1, and Treponema were enhanced after 21 days of Dex treatment; however, the levels of RC9_gut_group, Candidatus_Hepatincola, Desulfobulbus, and Desulfovibrio decreased (Fig. 5d). Parasutterella in the caecal digesta decreased in response to Dex (Fig. 5e). The abundances of Butyrivibrio and Anaerostipes increased in colonic digesta, whereas that of Anaeroplasma decreased in response to Dex (Fig. 5f). At the family level, the abundance of the BS11_gut_group increased in both the caecum and colonic digesta after Dex administration (Fig. 5e and F).

\section{Changes in methanogens}

Dex did not affect the structure of the methanogen community, as the PCoA plot spots did not separate at any of the time points examined (Fig. 6a-d). Class level methanogens were not affected by Dex (Additional file 6: Figure S6A-D). None of the methanogens was affected, 
Table 2 The component of VFA in caecum and colon

\begin{tabular}{|c|c|c|c|c|}
\hline \multirow[b]{2}{*}{ Parameters } & \multicolumn{2}{|l|}{ Caecum } & \multicolumn{2}{|l|}{ Colon } \\
\hline & Con & Dex & Con & Dex \\
\hline Acetate(mmol/L) & $10.86 \pm 1.15$ & $10.13 \pm 0.92$ & $10.04 \pm 0.67$ & $9.91 \pm 0.53$ \\
\hline Propionate(mmol/L) & $8.31 \pm 1.21$ & $6.39 \pm 0.72$ & $6.01 \pm 0.82$ & $5.72 \pm 0.62$ \\
\hline Isobutyrate(mmol/L) & $0.72 \pm 0.12$ & $0.62 \pm 0.09$ & $0.51 \pm 0.04$ & $0.67 \pm 0.18$ \\
\hline Butyrate(mmol/L) & $6.03 \pm 1.45$ & $4.24 \pm 0.48$ & $3.84 \pm 0.75$ & $3.09 \pm 0.26$ \\
\hline Isovalerate(mmol/L) & $0.51 \pm 0.09$ & $0.56 \pm 0.07$ & $0.38 \pm 0.04$ & $0.53 \pm 0.03^{*}$ \\
\hline Valerate(mmol/L) & $1.21 \pm 0.28$ & $1.02 \pm 0.15$ & $0.71 \pm 0.13$ & $0.72 \pm 0.10$ \\
\hline Caproate(mmol/L) & $1.01 \pm 0.40$ & $0.52 \pm 0.13$ & $0.47 \pm 0.02$ & $1.56 \pm 0.54$ \\
\hline Total(mmol/L) & $28.65 \pm 3.93$ & $23.69 \pm 2.81$ & $25.64 \pm 0.41$ & $22.19 \pm 1.38$ \\
\hline Ace/Pro & $1.33 \pm 0.08$ & $1.61 \pm 0.09^{\#}$ & $1.75 \pm 0.14$ & $1.78 \pm 0.10$ \\
\hline
\end{tabular}

Ace/Pro Acetate/propionate. Means \pm SE are plotted; $\# p<0.10,{ }^{*} p<0.05,{ }^{* *} p<0.01$ versus Con group

except Methanosphaera, which decreased on the final day of the Dex treatment (Fig. 7d).

\section{Discussion}

In the present study, ten male goats were randomly divided into two groups. Dex was used to make chronic stress model in the study. The object is to investigate the influence of chronic stress on the diversity of mircrobiota in the goats. However, the results showed that the microbita in the rumen, ceacum, and colon can resistant stress, even it had a great impact on the physiological metabolism.
WBCs increased significantly in response to Dex treatment in the present study, which may be a marker of animal welfare, consistent with a previous study [23]. As shown previously [24, 25], chronic Dex treatment significantly decreased DMI and body mass of growing goats, which may be attributable to the high level of blood glucose. As food intake decreased, resources for fermentation lessened, $\mathrm{pH}$ of the ruminal fluid increased after Dex administration, especially $2 \mathrm{~h}$ after the morning feeding on days 1 and 14 of the Dex treatment. However, the concentrations of rumen VFAs, which are produced by ruminal microorganism as an energy supplement, were not affected
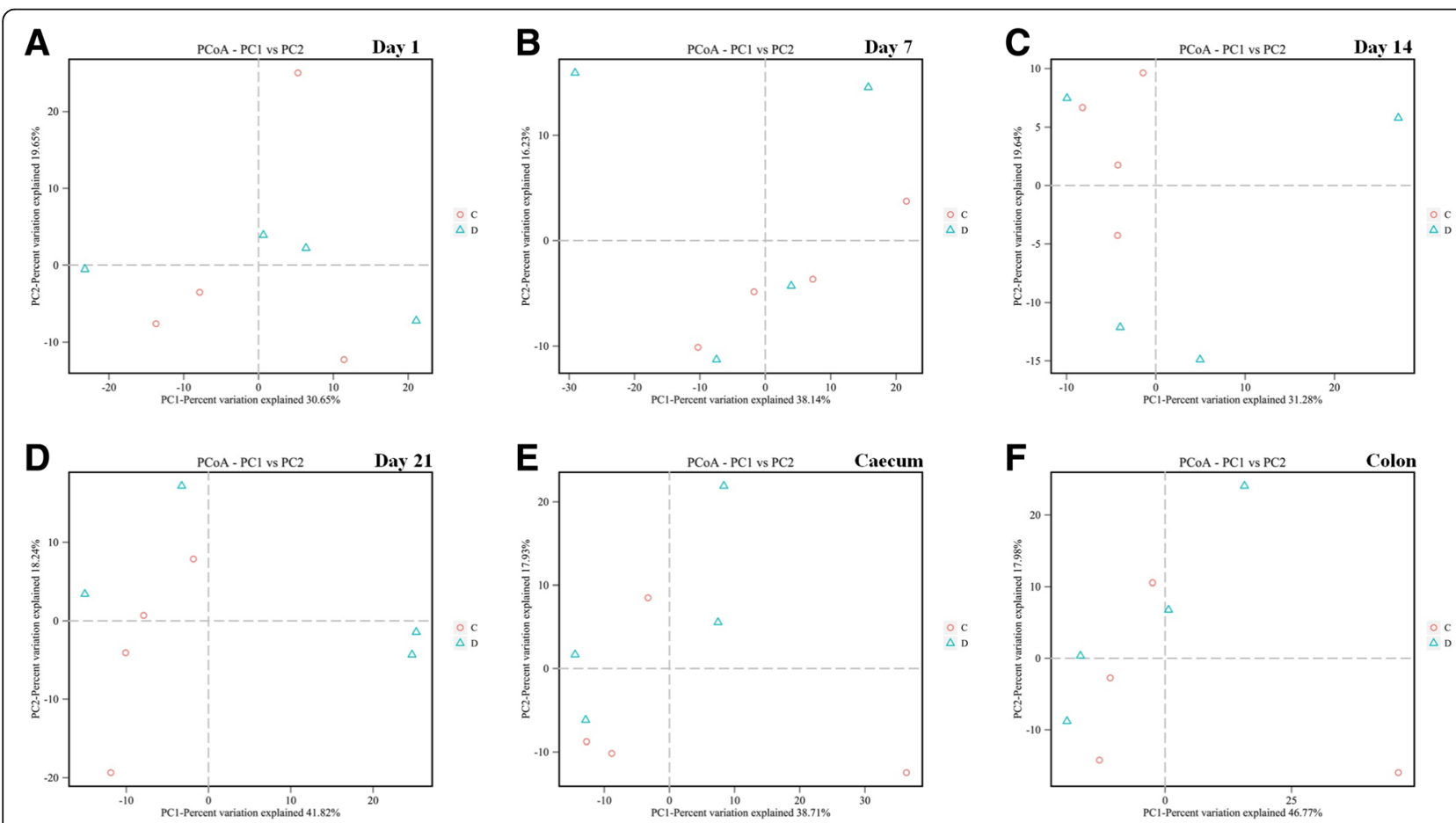

Fig. 4 Unweighted PCoA of bacteria microbiota in rumen fluid and the content of caecum and colon from goat treated with Dex or Con. a Day 1 in rumen. b Day 7 in rumen. c Day 14 in rumen. d Day 21 in rumen. e Content of caecum. $\mathbf{f}$ Content of colon 

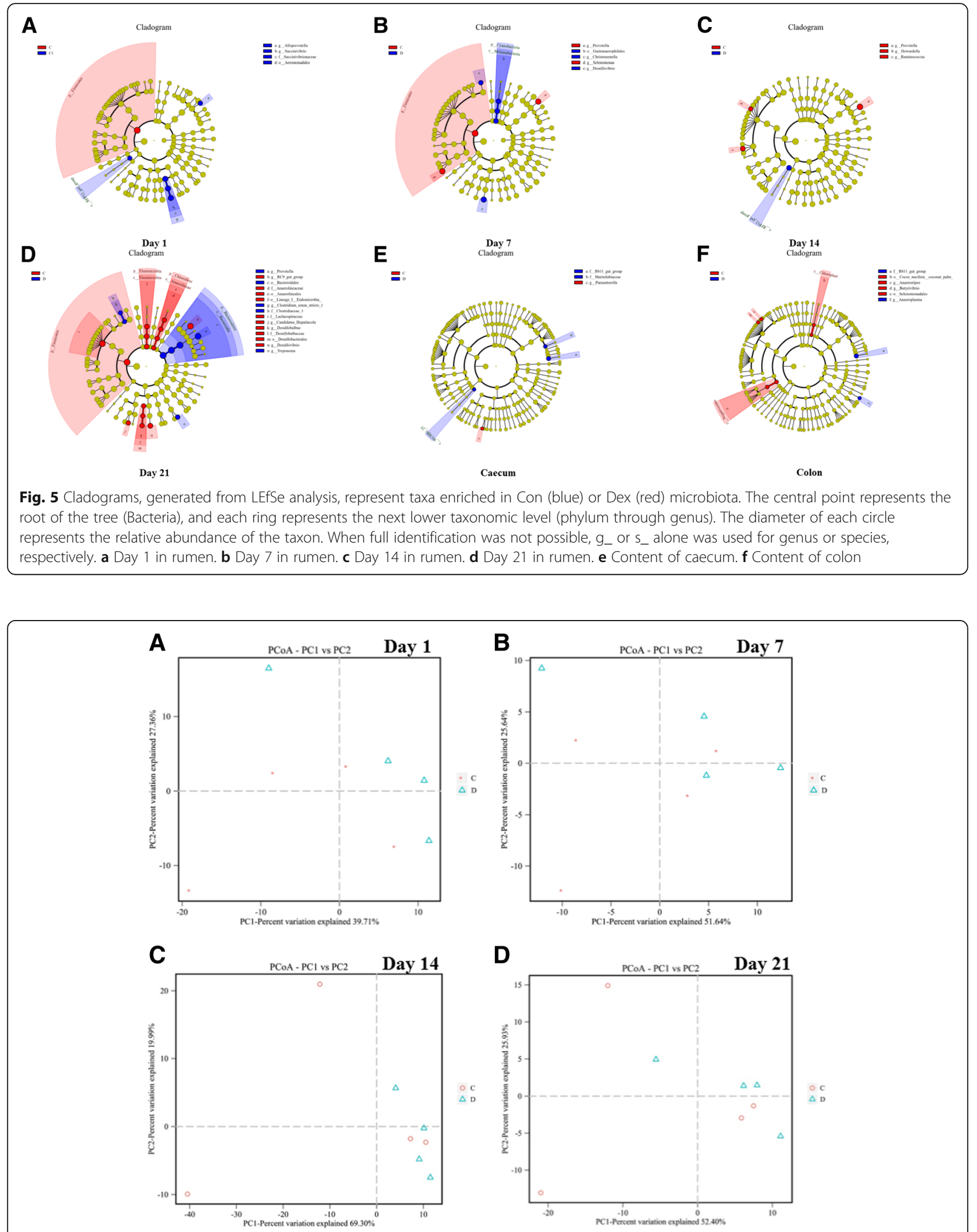

Fig. 6 Unweighted PCoA of methanogens in rumen fluid and the content of caecum and colon from goat treated with Dex or Con. a Day 1 in rumen. b Day 7 in rumen. $\mathbf{c}$ Day 14 in rumen. d Day 21 in rumen 


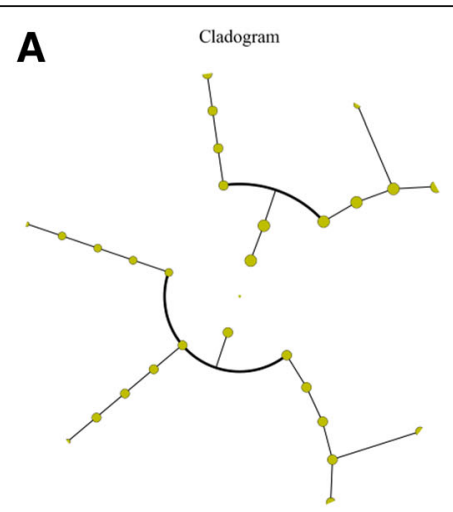

Day 1

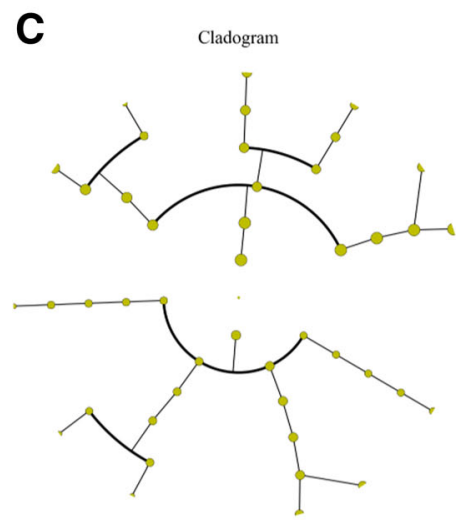

Day 14

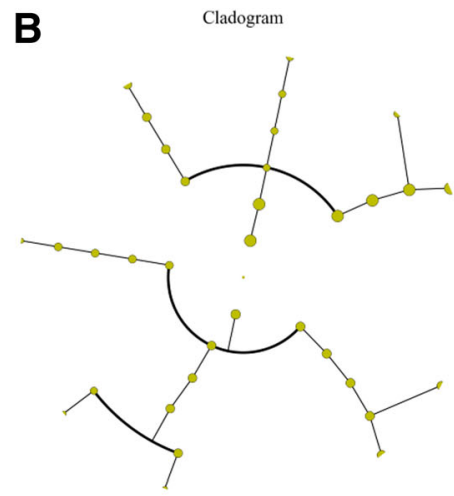

Day 7

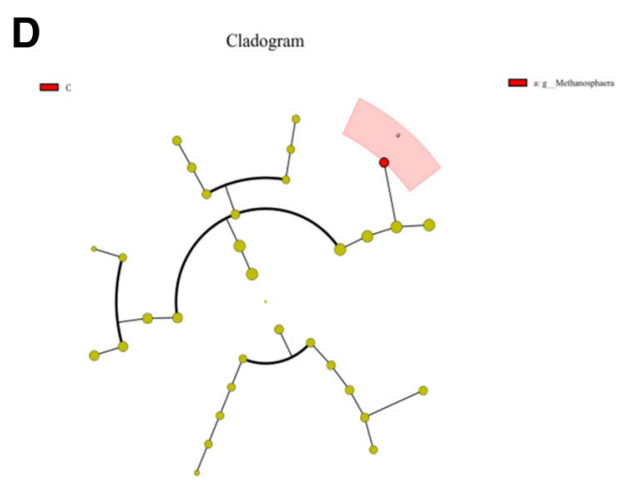

Day 21

Fig. 7 Cladograms, generated from LEfSe analysis, represent taxa enriched in Con (blue) or Dex (red) methanogens. The central point represents the root of the tree (methanogens), and each ring represents the next lower taxonomic level (phylum through genus). The diameter of each circle represents the relative abundance of the taxon. When full identification was not possible, g_ or s_ alone was used for genus or species, respectively. a Day 1 in rumen. b Day 7 in rumen. c Day 14 in rumen. d Day 21 in rumen

by Dex at any time during the experiment. Ruminal VFAs were changed significantly after the morning feeding on day 21 of the Dex treatment caused by a decrease in the DMI, which may have also reduced body mass. $\mathrm{pH}$, which is mainly influenced by lactic acid, did not decrease with the VFAs. However, the acetate/propionate ratio, which indicates different fermentation types, was unaffected [26]. None of the VFAs in the caecum or colon changed, as well as the acetate/propionate ratio, but colonic isovalerate concentration increased significantly and fecal butyrate decreased, leading to a significant decrease in total VFAs on days 14 and 21 of treatment. However, the acetate/propionate ratio remained unchanged. Ruminal urea and ammonia, as very important protein supplements, were not affected by Dex administration, suggesting that changes in body mass were not caused by the protein supplement. Increased plasma glucose and decreased plasma cortisol levels demonstrated that Dex stimulates gluconeogenesis and suppresses the cortisol secretion, consistent with previous studies $[1,27]$. Taken together, our results reveal that Dex changed the goat's metabolism.
Many studies have been performed about the interaction between the host and microbiota, and indicated that changes in the host's metabolism affect the composition of microbiota $[19,22]$. Stress can affect the composition of microbiota in rats $[15,28]$. We used next-generation sequence technology to detect the composition and community structure of the microbiota.

In the present study, the Dex effect on microbial community composition was measured by unweighted UniFrac distances ( $\beta$-diversity). The positions of the Dex and Con samples did not separate on the PCoA plot, suggesting that Dex did not affect the microbiota community structure. However, this result contrasts with a previous study in rats, showing that stress disrupted the microbiota community $[15,28]$. This difference may have been caused by the organs sampled or species differences. Interestingly, the relative abundance of bacteroidetes dominated other bacteria on day 21 in the Dex group, whereas the Con group was dominated by firmicutes. Several changes in the microbial population were seen from the phylum to the genus levels. 
Prevotella promotes increased hepatic glycogen storage in mice [29], which was consistent with the present study (data not shown), and was the only bacteria that changed at each sampling time. The strictly anaerobic bacteria Christensenella induces inflammation [30, 31], and Desulfovibrio, which removes zinc from wastewater [32], increased in the Dex group after 7 days of treatment, indicating that inflammation and zinc metabolism were disrupted. Prevotella and Selenomonas are representative nitrate- and nitrite-reducing bacteria, respectively that increased in the Con group. Increased abundances of Prevotella and Howardella, are caused by the high-concentrate diet and a reduction of DMI [33], and Ruminococcus, a mucosa-associated bacteria linked with gastrointestinal disease [34], increased on day 14 in the Con group, suggesting inflammation in the Con group and the anti-inflammatory activity of Dex. RC9 gut group and Candidatus, obligate anaerobic bacteria [35], and Desulfobulbaceae increased in the Con group on the last day of the experiment. Prevotella and Clostridiaceae, which play a role in pathogenesis [36], and Treponema, which shares a common ancestor with human pathogenic treponemes [37], increased in the Dex group on the last day of the experiment, demonstrating inflammation in the Dex group. Focusing on intestinal microbiota, the BS11_gut_group, family Bacteroidetes, was the only bacteria that increased in the caecum and colon after treatment, which is altered by a high-concentrate diet and reduced DMI [38]. Parasutterella increased in the caecum of the Con group. Anaerostipes, which utilize lactate [39] and Butyrivibrio, which ferment hemicelluloses [40], increased in the colon after treatment, demonstrated that fermentation was more effective in the Dex than in the Con groups. However, the VFAs did not change. Anaeroplasma, which is an obligate anaerobic bacterium [41], decreased in the colon after Dex treatment. Compared with a previous study [42], Dex increases total aerobes, total anaerobes, and Lactobacilli, but decreases Coliforms. However, we found contrasting results, which may have been caused by species differences.

These results suggest that Dex did not significantly affect the composition of the goat microbiota and only affected a few microbes. Those bacteria that were affected did not influence the fermentation type. We examined the changes in methanogenes, which produce methane and contribute to global warming [20]. The Dex and Con groups did not separate on the PCoA plot, suggesting that Dex did not disrupt the methanogen community structure, except Methanosphaera, which contains two species [43]. These results suggest that Dex did not affect the composition of methanogenes.

\section{Conclusions}

Taken together, Dex affected metabolism, such as food intake and glycometabolism, in goats. However, it did not disrupt the microorganismal community structure in the rumen, caecum, or colon. The complexity of the rumen may be the reason for the differences in our results with previous studies, where microorganisms can resist the impact of the host, but have dramatic effects on metabolism.

\section{Methods}

\section{Animals and experimental procedures}

Ten healthy male goats (body weight $25 \pm 1.0 \mathrm{~kg}$ ) fitted with ruminal cannulas were raised in individual pens with free access to water and fed twice daily at 08:00 $\mathrm{h}$ and 18:00 h, respectively. Goats were offered free access to the same diet containing $43 \%$ corn, $5 \%$ wheat bran, $17 \%$ mixed concentrate and $35 \%$ forage. Animals were accustomed to all procedures of sampling and treatment before treatments for two weeks. The dose of Dex was determined based on the previous study by Emikpe et al. [44]. Ten goats were randomly assigned to two groups: one group was injected intramuscularly with Dex, as Group I (Dex-Dexamethasone; $n=5), 0.2 \mathrm{mg} / \mathrm{kg}$, another group injected intramuscularly with the same volume saline $(0.9 \%)$ as Group II (Con-Control; $\mathrm{n}=5$ ), injection at 7:30 before morning feeding for 21 days.

\section{DMI measurement, plasma collection, and body weight}

Dry matter intake (DMI) was detected every day, before morning feeding. At 1, 7, 14, and 21 day, blood was sampled using heparin-containing vacuum tubes from jugular vein. Then $4{ }^{\circ} \mathrm{C}$ and $800 \times \mathrm{g}$ for $10 \mathrm{~min}$ centrifugation, extracted plasma in eppendorf and stored at $-20{ }^{\circ} \mathrm{C}$. At 14 and 21 day more blood samples were taken by using ethylenediaminetetraacetic acid containing vacuum tubes from jugular for blood routine examination. At the 21 day, the body weight had been measured.

\section{Feces, ruminal fluid, colonic and caecal content collection and assay}

We combined and adapted previously described methods to analyze feces, ruminal fluid, colonic and caecal content collection $[26,45,46]$. Feces were collected after morning feeding at $1,7,14$, and 21 day, shortly after collection, $5 \mathrm{~g}$ of fresh feces was dissolved with $5 \mathrm{~mL}$ of water. A portion of the extract was centrifuged at $2000 \times \mathrm{g}$ for $10 \mathrm{~min}$, and collected the supernatant. Then $1 \mathrm{~mL}$ of freshly prepared $25 \%$ metaphosphoric acid was added to $4 \mathrm{~mL}$ of the supernatant. The samples were then centrifuged $(17,000 \times \mathrm{g}$ for $10 \mathrm{~min})$, and the supernatant fluid was stored at $-20{ }^{\circ} \mathrm{C}$ prior to the determination of volatile fatty acids (VFAs). 
Samples of ruminal contents (approx. $50 \mathrm{~mL}$ ) were obtained on days $1,7,14$, and 21 of the experiment and at $0,2,4$, and $6 \mathrm{~h}$ after morning feeding. Contents of the rumen $(2 \mathrm{~mL})$ collected at $0 \mathrm{~h}$ during 4 days were stored at liquid nitrogen immediately, were used for DNA extraction. Other ruminal samples were strained through four layers of cheesecloth. The $\mathrm{pH}$ of the ruminal fluid was measured immediately after collection by a mobile $\mathrm{pH}$ meter. About $2 \mathrm{~mL}$ of freshly prepared $25 \%$ metaphosphoric acid was added to $8 \mathrm{~mL}$ of strained ruminal fluid. The samples were then centrifuged $(17,000 \times \mathrm{g}$ for $10 \mathrm{~min}$ ), and the supernatant fluid was stored at $-20{ }^{\circ} \mathrm{C}$ prior to the determination of VFAs. The remaining ruminal fluid samples were centrifuged at $12000 \times \mathrm{g}$ for 15 min at $4{ }^{\circ} \mathrm{C}$, and stored at $-20^{\circ} \mathrm{C}$ until analysis.

At the end of the experiment, goats were slaughtered after overnight fasting. All goats were weighed and killed with neck vein injections of xylazine $[0.5 \mathrm{mg} / \mathrm{kg}$ body weight; Xylosol; Ogris Pharme, Wels, Austria] and pentobarbital [50 mg/kg body weight; Release; WDT, Garbsen, Germany]. After death, the hind gut mucosal tissues were carefully removed. The content of caecum and colon were collected (approx. $50 \mathrm{~mL}$ ). $2 \mathrm{~mL}$ of the colonic and caecal content were stored at liquid nitrogen were used for DNA extraction. The remaining of colonic and caecal samples were centrifuged at $12000 \times \mathrm{g}$ for 15 min at $4{ }^{\circ} \mathrm{C}$, supernatant was collected. About $1 \mathrm{~mL}$ of freshly prepared $25 \%$ metaphosphoric acid was added to $4 \mathrm{~mL}$ of supernatant from caecum and colon. Then samples were centrifuged $(17,000 \times \mathrm{g}$ for $10 \mathrm{~min})$, and the supernatant fluid was stored at $-20{ }^{\circ} \mathrm{C}$ prior to the determination of VFAs.

\section{Blood parameters detection}

Plasma glucose was measured using an automatic biochemical analyzer (7020, HITACHI, Tokyo, Japan). Cortisol was detected by using RIA cortisol kit (Beijing North Institute of Biological Tec.), strictly following the manufacturer's instructions.

\section{Urea and ammonia detection}

The rumen fluid samples were taken out of $-20{ }^{\circ} \mathrm{C}$ refrigerator. Then defreeze samples in room temperature. Berthelot (phenol-hypochlorite) reaction was used to determine NH3-N concentration [47]. The discetyl monoxime method was used to detect Urea-N level by a commercial kit (Nanjing Jiancheng Co., Nanjing, China).

\section{DNA extraction and 16S rRNA gene amplicon pyrosequencing}

The methods of DNA extraction and 16S rRNA gene amplicon pyrosequencing were described previously [26]. $2 \mathrm{~mL}$ fluid from each goat collected was used for DNA extraction. The DNA samples were stored at $-80{ }^{\circ} \mathrm{C}$ until further processing. DNA purity was verified through agar gel electrophoresis. And the DNA was used as template to amplify the 16S V3-V4 region, amplificated with specific primers with Barcode. The primers used for the bacterial 16S rRNA hypervariable region (V3-V4) were 343F (5'-TACG GRAGGCAGCAG-3') and 798R (5'-AGGGTATCTAATC CT-3') [48], and the primers for archaeal $16 \mathrm{~S}$ rRNA hypervariable region (V4-V5) were Arch519F (5'-CAGC MGCCGCGGTAA-3') and Arch915R (5'-GTGCTCCCC CGCCAATTCCT-3') [49]. The efficient hi-fi PCR enzyme and the Phusion ${ }^{\circ}$ High-Fidelity PCR Master Mix with GC Buffer (New England Biolabs) were added to insure the amplification efficiency and accuracy. Then we made the database with the TruSeq ${ }^{\circ}$ DNA PCR-Free Sample preparation Kit, and then used HiSeq2500 PE250 to sequencing.

Raw tags were got by the FLASH (version 1.2.7). Further, high quality clean tags were obtained through strict filtering processing by the Quantitative insights into microbial ecology (Qiime) (version 1.7.0). Effective tags were clustered to the Operational Taxonomic Units (OTUs) by Uparse (version 7.0.1001). The RDP classifier (version 2.2) and GreenGene database were used to species annotation. The unweighted principal component analysis (PCoA) analysis was made by the $\mathrm{R}$ (version 2.15.3). Linear discriminant analysis effect size (LEfSe) was used to detect significant changes in relative abundance of microbial taxa (LDA $>2$ ).

\section{Statistical analysis}

Data are presented as means \pm SE. The data were tested for normal distribution and analyzed by Student's unpaired $t$ test using SPSS software packages (SPSS version 19.0 for Windows; SPSS Inc., Chicago, IL, USA). Data were considered statistically significant when $p<0.05$. The numbers of replicates used for statistics were noted in the figures.

\section{Additional files}

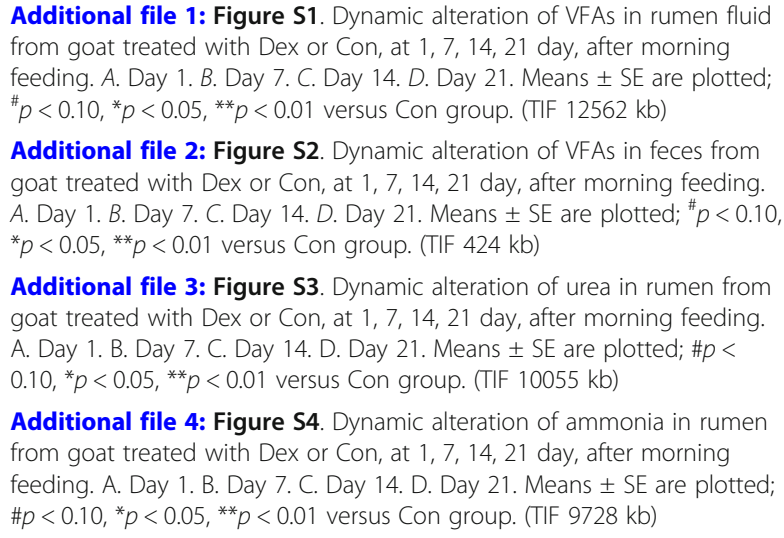

Additional file 1: Figure S1. Dynamic alteration of VFAs in rumen fluid from goat treated with Dex or Con, at 1, 7, 14, 21 day, after morning feeding. A. Day 1. B. Day 7. C. Day 14. D. Day 21. Means \pm SE are plotted; ${ }^{\#} p<0.10,{ }^{*} p<0.05,{ }^{* *} p<0.01$ versus Con group. (TIF $12562 \mathrm{~kb}$ )

Additional file 2: Figure S2. Dynamic alteration of VFAs in feces from goat treated with Dex or Con, at 1, 7, 14, 21 day, after morning feeding. A. Day 1. B. Day 7. C. Day 14. D. Day 21. Means \pm SE are plotted; ${ }^{*} p<0.10$, ${ }^{*} p<0.05,{ }^{* *} p<0.01$ versus Con group. (TIF $424 \mathrm{~kb}$ )

Additional file 3: Figure S3. Dynamic alteration of urea in rumen from goat treated with Dex or Con, at 1, 7, 14, 21 day, after morning feeding. A. Day 1. B. Day 7. C. Day 14. D. Day 21. Means \pm SE are plotted; \#p< $0.10,{ }^{*} p<0.05,{ }^{* *} p<0.01$ versus Con group. (TIF $10055 \mathrm{~kb}$ )

Additional file 4: Figure S4. Dynamic alteration of ammonia in rumen from goat treated with Dex or Con, at 1, 7, 14, 21 day, after morning feeding. A. Day 1. B. Day 7. C. Day 14. D. Day 21. Means \pm SE are plotted; $\# p<0.10,{ }^{*} p<0.05,{ }^{* *} p<0.01$ versus Con group. (TIF $9728 \mathrm{~kb}$ ) 
Additional file 5: Figure S5. Altering compositions of microbial phylum (as a percentage of the total sequence), in rumen, caecum, and colon from goat treated with Dex or Con. A. Day 1 in rumen. B. Day 7 in rumen. C. Day 14 in rumen. D. Day 21 in rumen. E. Content of caecum. F. Content of colon. (TIF $8329 \mathrm{~kb}$ )

Additional file 6: Figure S6. Altering compositions of methanogenic class (as a percentage of the total sequence), in rumen, caecum, and colon from goat treated with Dex or Con. A. Day 1 in rumen. B. Day 7 in rumen. C. Day 14 in rumen. D. Day 21 in rumen. E. Content of caecum. F. Content of colon. (TIF $13224 \mathrm{~kb}$ )

\section{Abbreviations}

Dex: Dexamethasone; DMI: Dry matter intake; OTU: Operational taxonomic unit; PCOA: Principal component analysis; VFA: Volatile fatty acid

\section{Funding}

This work was supported by the National Nature Science Foundation of China (project no. 31272470). The funding body had no role in the design of the study and collection, analysis, and interpretation of data at the same in writing the manuscript.

\section{Availability of data and materials}

The raw sequence data, corresponding metadata, quality filtered reads, representative sequences and taxonomy assignments to the representative sequences of this study are available in figshare.com (https://figshare.com/s/ b3b97fc1f3f7b7885642).

\section{Authors' contributions}

$\mathrm{CH}$ and YG analyzed the data, contributed reagents/materials/analysis tools, wrote the paper, prepared figures and/or tables, reviewed drafts of the paper. QC and LN performed the experiments, contributed reagents/ materials/analysis tools, wrote the paper. CH, LC and ST participated in the writing and drafting of the manuscript; $\mathrm{CH}, \mathrm{YN}$ and RZ conceived and designed the experiments, wrote the paper, reviewed drafts of the paper. All authors read and approved this final manuscript.

\section{Ethics approval and consent to participate}

Goats that were donors of rumen fluid were maintained according to the ethics committee and Institutional Animal Care and Use Committee standards for the Nanjing Agricultural University. Experiments were performed in accordance with the Regulations for the Administration of Affairs Concerning Experimental Animals (The State Science and Technology Commission of P. R. China, 1998)

\section{Consent for publication}

Not applicable.

\section{Competing interests}

The authors declare that they have no competing interests.

\section{Publisher's Note}

springer Nature remains neutral with regard to jurisdictional claims in published maps and institutional affiliations.

Received: 19 March 2018 Accepted: 28 August 2018

Published online: 10 September 2018

\section{References}

1. Silanikove $\mathrm{N}$. Effects of heat stress on the welfare of extensively managed domestic ruminants. Livest Prod Sci. 2000;67:1):1-18.

2. Terry L, Willoughby J, Braseau P, Martin J, Patel Y. Antiserum to somatostatin prevents stress-induced inhibition of growth hormone secretion in the rat. Science. 1976;192(4239):565-7.

3. Tamashiro KL, Sakai RR, Shively CA, Karatsoreos IN, Reagan LP. Chronic stress, metabolism, and metabolic syndrome. Stress. 2011;14(5):468-74.

4. Capes SE, Hunt D, Malmberg K, Gerstein HC. Stress hyperglycaemia and increased risk of death after myocardial infarction in patients with and without diabetes: a systematic overview. Lancet. 2000;355(9206):773-8.
5. Van den Berghe G. Molecular biology: a timely tool for further unraveling the "diabetes of stress". Crit Care Med. 2001;29(4):910-1.

6. Laird AM, Miller PR, Kilgo PD, Meredith JW, Chang MC. Relationship of early hyperglycemia to mortality in trauma patients. J Trauma Acute Care Surg. 2004;56(5):1058-62.

7. Capes SE, Hunt D, Malmberg K, Pathak P, Gerstein HC. Stress hyperglycemia and prognosis of stroke in nondiabetic and diabetic patients. Stroke. 2001; 32(10):2426-32.

8. Kuo T, Harris CA, Wang J-C. Metabolic functions of glucocorticoid receptor in skeletal muscle. Mol Cell Endocrinol. 2013;380(1):79-88.

9. Losser M-R, Damoisel C, Payen D. Bench-to-bedside review: glucose and stress conditions in the intensive care unit. Crit Care. 2010;14(4):231.

10. Freestone $P$, Lyte M. Stress and microbial endocrinology: prospects for ruminant nutrition. Animal. 2010;4(7):1248-57

11. Shamay A, Mabjeesh S, Shapiro F, Silanikove N. Adrenocorticotrophic hormone and dexamethasone failed to affect milk yield in dairy goats: comparative aspects. Small Rumin Res. 2000;38(3):255-9.

12. Bäckhed F, Ding H, Wang T, Hooper LV, Koh GY, Nagy A, Semenkovich CF, Gordon JI. The gut microbiota as an environmental factor that regulates fat storage. Proc Natl Acad Sci U S A. 2004;101(44):15718-23.

13. Ley RE, Bäckhed F, Turnbaugh P, Lozupone CA, Knight RD, Gordon Jl. Obesity alters gut microbial ecology. Proc Natl Acad Sci U S A. 2005;102(31):11070-5.

14. O'Hara AM, Shanahan F. The gut flora as a forgotten organ. EMBO Rep. 2006;7(7):688-93.

15. Bailey MT, Dowd SE, Galley JD, Hufnagle AR, Allen RG, Lyte M. Exposure to a social stressor alters the structure of the intestinal microbiota: implications for stressor-induced immunomodulation. Brain Behav Immun. 2011;25(3):397-407.

16. Bailey MT, Dowd SE, Parry NM, Galley JD, Schauer DB, Lyte M. Stressor exposure disrupts commensal microbial populations in the intestines and leads to increased colonization by Citrobacter rodentium. Infect Immun. 2010;78(4):1509-19.

17. Söderholm JD, Yang PC, Ceponis P, Vohra A, Riddell R, Sherman PM, Perdue $\mathrm{MH}$. Chronic stress induces mast cell-dependent bacterial adherence and initiates mucosal inflammation in rat intestine. Gastroenterology. 2002;123(4):1099-108.

18. Albor AR, Martínez-Becerril E, Arciniega-Martínez I, Salas-Pimentel M, GarcíaFonseca A, Campos-Rodríguez R. Effect of acute stress on B cells and IgA production of large intestine. Brain Behav Immun. 2015:49:e35.

19. Pitlik SD, Koren O. How holobionts get sick-toward a unifying scheme of disease. Microbiome. 2017:5(1):64.

20. Opio C, Gerber P, Mottet A, Falcucci A, Tempio G, MacLeod M, Vellinga T, Henderson B, Steinfeld $\mathrm{H}$. Greenhouse gas emissions from ruminant supply chains-a global life cycle assessment. Rome: Food and agriculture organization of the United Nations (FAO); 2013.

21. Conrad R. The global methane cycle: recent advances in understanding the microbial processes involved. Environ Microbiol Rep. 2009;1(5):285-92.

22. Kurilshikov A, Wijmenga C, Fu J, Zhernakova A. Host genetics and gut microbiome: challenges and perspectives. Trends Immunol. 2017;

23. Anderson B, Watson D, Colditz I. The effect of dexamethasone on some immunological parameters in cattle. Vet Res Commun. 1999;23(7):399-413.

24. Jahng JW, Kim NY, Ryu V, Yoo SB, Kim B-T, Kang D-W, Lee J-H. Dexamethasone reduces food intake, weight gain and the hypothalamic 5-HT concentration and increases plasma leptin in rats. Eur J Pharmacol. 2008;581(1):64-70.

25. Alario P, Gamallo A, Beato M, Trancho G. Body weight gain, food intake and adrenal development in chronic noise stressed rats. Physiol Behav. 1987:40(1):29-32.

26. Hua C, Tian J, Tian P, Cong R, Luo Y, Geng Y, Tao S, Ni Y, Zhao R. Feeding a high concentration diet induces unhealthy alterations in the composition and metabolism of ruminal microbiota and host response in a goat model. Front Microbiol. 2017;8

27. Cartmill J, Thompson D, Gentry L, Pruett H, Johnson C. Effects of dexamethasone glucose infusion, adrenocorticotropin, and propylthiouracil on plasma leptin concentrations in horses. Domest Anim Endocrinol. 2003:24(1):1-14.

28. Bharwani A, Mian MF, Foster JA, Surette MG, Bienenstock J, Forsythe $P$. Structural \& functional consequences of chronic psychosocial stress on the microbiome \& host. Psychoneuroendocrinology. 2016;63:217-27.

29. Kovatcheva-Datchary P, Nilsson A, Akrami R, Lee YS, De Vadder F, Arora T, Hallen A, Martens E, Björck I, Bäckhed F. Dietary fiber-induced improvement in glucose metabolism is associated with increased abundance of Prevotella. Cell Metab. 2015;22(6):971-82. 
30. Morotomi M, Nagai F, Watanabe Y. Description of Christensenella minuta gen. Nov., sp. nov., isolated from human faeces, which forms a distinct branch in the order Clostridiales, and proposal of Christensenellaceae fam. Nov. Int J Syst Evol Microbiol. 2012;62(1):144-9.

31. Alonso BL, von Sierakowski Al, Nieto JAS, Rosel AB. First report of human infection by Christensenella minuta, a gram-negative, strickly anaerobic rod that inhabits the human intestine. Anaerobe. 2017:44:124-5.

32. Kim IH, Choi J-H, Joo JO, Oh B-K. Development of microbe carrier for bioremediation of Zn, as by using Desulfovibrio Desulfuricans and zeolite in Artificial Sea water. KSBB Journal. 2015;30(3):114-8.

33. Liu J-h, G-r B, W-y Z, S-y M. High-grain feeding causes strong shifts in ruminal epithelial bacterial community and expression of toll-like receptor genes in goats. Front Microbiol. 2015;6

34. Wang L, Christophersen CT, Sorich MJ, Gerber JP, Angley MT, Conlon MA. Increased abundance of Sutterella spp. and Ruminococcus torques in feces of children with autism spectrum disorder. Molecular autism. 2013;4(1):42.

35. Schmid M, Walsh K, Webb R, Rijpstra WI, Van de pas-Schoonen K, Verbruggen MJ, hill T, Moffett B, Fuerst J, Schouten S. Candidatus "Scalindua brodae", sp. nov., Candidatus "Scalindua wagneri", sp. nov., two new species of anaerobic ammonium oxidizing bacteria. Syst Appl Microbiol. 2003;26(4):529-38.

36. Scarpa M, Grillo A, Pozza A, Faggian D, Ruffolo C, Scarpa M, D'Incà R, Plebani M, Sturniolo GC, Castagliuolo I. TLR2 and TLR4 Up-regulation and Colonization of the lleal Mucosa by Clostridiaceae spp. in Chronic/Relapsing Pouchitis 1, 2. J Surg Res. 2011;169(2):e145-54.

37. Radolf JD, Deka RK, Anand A, Šmajs D, Norgard MV, Yang XF. Treponema pallidum, the syphilis spirochete: making a living as a stealth pathogen. Nat Rev Microbiol. 2016;14(12):744-59.

38. Liu J, Bian G, Sun D, Zhu W, Mao S. Starter feeding supplementation alters colonic mucosal bacterial communities and modulates mucosal immune homeostasis in newborn lambs. Front Microbiol. 2017;8:429.

39. Sato T, Matsumoto K, Okumura T, Yokoi W, Naito E, Yoshida Y, Nomoto $\mathrm{K}$, Ito $M$, Sawada $\mathrm{H}$. Isolation of lactate-utilizing butyrate-producing bacteria from human feces and in vivo administration of Anaerostipes caccae strain L2 and galacto-oligosaccharides in a rat model. FEMS Microbiol Ecol. 2008;66(3):528-36.

40. Emerson EL, Weimer PJ. Fermentation of model hemicelluloses by Prevotella strains and Butyrivibrio fibrisolvens in pure culture and in ruminal enrichment cultures. Appl Microbiol Biotechnol. 2017;101(10):4269-78.

41. Robinson i, Allison m, Hartman p. Anaeroplasma abactoclasticum gen. Nov., sp. nov.: an obligately anaerobic mycoplasma from the rumen. Int J Syst Evol Microbiol. 1975;25(2):173-81.

42. Ünsal H, Balkaya M, Ünsal C, Bıyık H, Başbülbül G, Poyrazoğlu E. The shortterm effects of different doses of dexamethasone on the numbers of some bacteria in the ileum. Dig Dis Sci. 2008;53(7):1842-5.

43. Dridi B, Henry M, El Khechine A, Raoult D, Drancourt M. High prevalence of Methanobrevibacter smithii and Methanosphaera stadtmanae detected in the human gut using an improved DNA detection protocol. PLoS One. 2009;4(9):e7063.

44. Obukowho Emikpe B, Tanko PN, Mayowa Onilude O, Yussof Sabri M. The influence of dexamethasone treatment and successive road transport stress on the occurrence of caprine pneumonia in a hot humid tropical environment. Veterinary World. 2013;6(8):497-501.

45. Tao S, Duanmu Y, Dong H, Ni Y, Chen J, Shen X, Zhao R. High concentrate diet induced mucosal injuries by enhancing epithelial apoptosis and inflammatory response in the hindgut of goats. PLoS One. 2014;9(10):e111596.

46. Mao S, Zhang R, Wang D, Zhu W. The diversity of the fecal bacterial community and its relationship with the concentration of volatile fatty acids in the feces during subacute rumen acidosis in dairy cows. BMC Vet Res. 2012;8:237.

47. Broderick $G$, Kang J. Automated simultaneous determination of ammonia and total amino acids in ruminal fluid and in vitro media1. J Dairy Sci. 1980;63(1):64-75.

48. Nossa CW, Oberdorf WE, Yang L, Aas JA, Paster BJ, DeSantis TZ, Brodie EL, Malamud D, Poles MA, Pei Z. Design of 165 rRNA gene primers for 454 pyrosequencing of the human foregut microbiome. World Journal of Gastroenterology : WJG. 2010;16(33):4135-44.

49. Teske A, Sørensen KB. Uncultured archaea in deep marine subsurface sediments: have we caught them all? The Isme Journal. 2007;2:3.

\section{Ready to submit your research? Choose BMC and benefit from:}

- fast, convenient online submission

- thorough peer review by experienced researchers in your field

- rapid publication on acceptance

- support for research data, including large and complex data types

- gold Open Access which fosters wider collaboration and increased citations

- maximum visibility for your research: over $100 \mathrm{M}$ website views per year

At BMC, research is always in progress.

Learn more biomedcentral.com/submissions 